\title{
Randomized clinical trials in periodontology: focus on outcomes selection
}

\section{Claudio Mendes PANNUTI (a) Fernando Oliveira COSTA ${ }^{(b)}$ Nathalia Vilela SOUZA(a) \\ Belen RETAMAL-VALDES ${ }^{(c)}$ \\ Amanda Almeida COSTA ${ }^{(b)}$ (D) \\ Cristiano SUSIN(d) (D) \\ Magda FERES(c)}

(a) Universidade de São Paulo - USP, School of Dentistry, Department of Stomatology, São Paulo, SP, Brazil.

(b) Universidade Federal de Minas Gerais UFMG, School of Dentistry, Department of Clinic, Pathology and Dental Surgery, Belo Horizonte, MG, Brazil.

(c) Universidade Guarulhos - UNG, Dental Research Division, Department of Periodontology and Oral Implantology, Guarulhos, SP, Brazil.

(d) University of North Carolina at Chapel Hill, Adams School of Dentistry, Division of Comprehensive Oral Health -

Periodontology, Chapel Hill, NC, USA.

Declaration of Interests: The authors certify that they have no commercial or associative interest that represents a conflict of interest in connection with the manuscript.

Corresponding Author:

Claudio Mendes Pannuti

E-mail:pannuti@usp.br

hitps://doi.org/10.1590/1807-3107bor-2021.vol35.0100

Submitted: March 12, 2021

Accepted for publication: March 31, 2021

Last revision: April 9, 2021
Abstract: Randomized clinical trials (RCTs) are human studies carried out to compare different treatments or interventions, and their results are used to support clinical decision-making and improve patient care. Herein, the aim of this study was to review the selection process of study outcomes in periodontology. Primary outcomes should draw the main conclusions of the study, whereas secondary outcomes should only be used to help explain the main findings and generate future research hypothesis. Outcomes are classified as clinically relevant (CROs) or surrogate outcomes. CROs - the first option for primary outcome variables - should convey not only substantial health benefits, but also be deemed important by patients. In periodontology, tooth loss/retention and oral health-related quality of life (OHRQoL) are examples of CROs. While tooth loss has main limitations as a primary outcome, emerging evidence suggest that patient-reported outcome measures (PROMs) can accurately detect OHRQoL following periodontal therapy. When CROs cannot be assessed, validated surrogate outcomes can be used as proxies. Primary outcome variables should reflect a treatment endpoint at the patient level that can be easily used to inform decision-making in daily practice. These outcomes should allow the implementation of a treat-to-target concept in which the intervention can be clearly judged against a prespecified treatment target. Recently, the presence of at most 4 sites with periodontal probing depth $\geq 5 \mathrm{~mm}$ post-treatment was suggested as an effective endpoint for periodontal trials. In perspective, a combination of validated clinical parameters and PROMs will provide a more comprehensive assessment of periodontal treatments.

Keywords: Clinical Trial; Treatment Outcome.

\section{Introduction}

Randomized clinical trials (RCTs) are considered the gold standard study design for the evaluation of the efficacy and safety of interventions in health care settings. ${ }^{1}$ This is accomplished by randomly assigning participants to experimental groups and then comparing groups in relation to important health outcomes, also referred to as "dependent variables" or "endpoints". The selection of an appropriate study outcome is essential during the planning stages of a RCT. Poorly chosen outcomes may lead to findings that do not translate into true benefits for patients. 
Ideally, investigators should select study outcomes that not only provide substantial health benefits, but also are deemed important by patients. Regulatory agencies, including the Food and Drug Administration, currently favor outcomes that measure "how a patient feels, functions or survives". In this context, most trials in periodontology have focused on clinician-centered outcomes (e.g.: periodontal probing depth [PPD] reduction, clinical attachment level [CAL] gain, and radiographic bone loss) that do not capture the expectations and perceptions of the patient.

Thus, the aim of this paper was to review the selection process of study outcomes in periodontology.

\section{Primary and secondary outcomes}

Most RCTs in dentistry explore multiple outcomes in order to assess the effects and, sometimes, safety of dental treatments and interventions. In this context, outcomes can be categorized into primary and secondary. A primary outcome is defined as the outcome that the investigator consider to be the most important among the parameters that will be assessed in the trial. ${ }^{2,3}$ Primary outcomes address the main research question of the study, and consequently, determine the study design and sample size, and support the main conclusion of the study. In contrast, secondary outcomes are exploratory in nature; strictly speaking the trial is not designed to evaluate them. Findings based on secondary outcomes should not be used to draw definitive conclusions. Nevertheless, they can help to explain the primary outcomes or generate hypotheses to be explored in future trials. Preferably, the primary outcome should be a clinically relevant outcome (CRO). If it is not feasible to select a CRO as the primary outcome, a validated surrogate outcome can be used as a proxy. It is important to acknowledge that depending on the objective of the study a given outcome can be primary or secondary. For instance, pain/discomfort can be a primary outcome in a trial testing an analgesic and secondary in a trial testing a new surgical technique.

Important clinical research guidelines, including Standard Protocol Items: Recommendations for
Interventional Trials (SPIRIT), ${ }^{2}$ Consolidated Standards of Reporting Trials (CONSORT) ${ }^{3}$ and International Council for Harmonisation (ICH), ${ }^{4}$ recommend the use of a single primary outcome in order to prevent multiplicity. ${ }^{5}$ Multiplicity occurs when multiple comparisons are carried out during statistical analysis, for instance, comparison of multiple outcomes over multiple time periods (fishing expedition probability or data-fishing). Multiplicity increases the probability of type I error, which is the incorrect rejection of the null-hypothesis resulting in the mistaken conclusion that a treatment is better than the comparison intervention, when in fact it is not. ${ }^{6,7}$ This may lead to the unethical reporting of the most favorable results. ${ }^{6,7}$

All outcomes, primary and secondary, must be pre-specified in the research protocol, which should be available on a public platform prior to study initiation. Several public and private clinical trial registries are currently available, including the World Health Organization International Clinical Trials Registry Platform (ICTRP), United States National Institutes of Health (Clinicaltrials.gov) and Brazilian Clinical Trials Registry (ReBec). Failure to register the protocol before the study starts can result in publication bias and selective outcome reporting (SOR). Publication bias occurs when the results of a trial influence the decision whether to publish it or not. On the other hand, SOR is a type of reporting bias that happens when the primary outcome of the study registry is modified or suppressed, or when a new outcome is added in the final publication. ${ }^{8,9}$ Prespecification of primary and secondary outcomes in a public database has been shown to reduce publication bias and SOR.

Outcomes must be completely described using the following five levels of specification in reporting outcome measures. ${ }^{10,11}$ domain, measurement, metric, data aggregation method, and time point..$^{10}$ An example of a completely defined outcome is "mean PPD reduction after 12-months of follow-up in sites with PPD $\geq 5 \mathrm{~mm}$ at baseline". If one of these five elements is absent or unclear, the outcome is not completely defined, setting precedents for "cherry-picking", which is the selective reporting of certain outcome measurements or time points. ${ }^{11}$ 


\section{Clinically relevant outcomes and surrogate outcomes}

Researchers should select primary and secondary outcomes that are important and tangible to patients. These types of outcome are usually referred as CROs, and are also called true, direct or clinically meaningful outcomes. ${ }^{12}$ Examples include death, tooth loss, number of hospitalizations, pain/discomfort and quality of life (QoL). Some CROs are reported by patients and are called patient-reported outcome measures (PROMs). Objective CROs, such as all-cause mortality or tooth loss, are rarely chosen as the primary outcome for clinical trials, because they are infrequent events and require several years of follow-up. Thus, objective CROs are frequently replaced by surrogate outcomes. Surrogate outcomes include post-treatment changes in biomarkers (e.g. gingival crevicular fluid levels of interleukin-1 $\beta$ ), in radiographic (e.g. alveolar bone loss) or clinical parameters (e.g. mean PPD) that are not themselves a direct measurement of the clinical endpoint for treatment. ${ }^{13}$ Rather, they are supposed to be a proxy for the true CRO. Investigators often use surrogate outcomes in order to reduce the study sample size, follow-up and costs.

The effects of the intervention on the surrogate outcome are supposed to reliably predict a substantial effect on the CRO. Whereas some surrogates have a strong causal association with the real condition (e.g. intra-ocular pressure and glaucoma), others fail to demonstrate a correlation with the disease and its consequences (e.g. blood glucose and cardiovascular events in diabetic subjects). ${ }^{14}$ Before a surrogate outcome is chosen as the primary outcome, it should be properly validated. ${ }^{13}$

\section{Clinically Relevant Outcomes (CROs) in periodontal trials}

The choice of study outcome in periodontal clinical trials has been a great challenge for the field. In fact, the interpretation of the findings from clinical trials testing different periodontal treatments and the extrapolation of these findings to clinical practice have been hampered by the heterogeneity and subjectivity of the outcome measures used in different studies.
In periodontal clinical trials, tooth loss/retention and oral health-related quality of life (OHRQoL), assessed by PROMs, could be considered as preferred CROs. Although some authors have advocated for tooth loss, ${ }^{152}$ there are several difficulties associated with the use of this parameter. First, spontaneous tooth loss after treatment is an infrequent event since extraction of teeth with very advanced disease is part of the initial therapy ${ }^{163}$ Thus, any reduction in tooth loss attributable to the experimental treatment would require several years of follow-up (e.g., 5-10 years) to be detected. Second, the relationship between oral health and tooth loss/retention depends not only on caries and periodontitis progression, but also on cultural beliefs, socio-economic characteristics, demographics, behavioral variables, and dental care philosophy. Therefore, tooth loss/retention is not frequently used as a primary outcome in RCTs testing periodontal treatments.

PROMs are a promising option for assessing CROs in periodontal trials. These parameters can be broadly understood as "measurements of any aspect of a patient's health status that come directly from the patient ${ }^{\prime 17}$ and that facilitates a comprehensive approach to patient assessment frequently identifying problems that are overlooked in routine practice. PROMs are powerful tools to inform patients and clinicians about morbidity and 'patient suffering', especially in chronic diseases. PROMs provide information on the patient experience and can be the target of therapeutic intervention and improve the quality of patient care by creating a holistic approach to clinical decision-making. ${ }^{17}$ PROMs are currently used in regulatory decisions, including submissions to the Food and Drug Administration and European Medicines Agency, as a measure of the patient's perspective on the performance of medical devices and treatments. PROMs can assess subjective CROs that are used as primary outcomes depending on the disease/condition being studied.

Collecting PROM data is an effective way to standardize practice and improve patient management. Whether PROMs can improve the quality of patient care remains under debate. ${ }^{17}$ Over the past two decades, several studies have measured the impact of oral health on QoL. ${ }^{18}$ These QoL measures, which 
were initially designated as socio-dental indicators or subjective indicators of oral health, are now more commonly referred to as self-reported QoL measures related to oral health. ${ }^{17}$ Particularly, studies have shown a significant association between periodontitis and OHRQoL. ${ }^{19,20,21}$ Periodontitis clinical consequences may negatively impact QoL regarding emotional, social and functional aspects as well as symptoms in acute processes and the severity of the disease. ${ }^{22,23}$

Few RCTs have investigated the effect of periodontal treatment on OHRQoL. ${ }^{21,24-29}$ Although limited in their number and scope, the overall findings indicate a positive impact of periodontal interventions on OHRQoL (Table 1). Several RCTs have evaluated the effect of implant dentistry on
PROMs showing a positive effect of removable and fixed implant-supported prostheses on patient satisfaction and QoL. ${ }^{30}$ Similarly, RCTs comparing different treatment options for gingival recession have shown that certain surgical techniques had a significant impact on patient's aesthetic satisfaction and post-operative morbidity. ${ }^{31}$

RCTs that use PROM endpoints follow similar study design and methodology than those focusing on clinical endpoints. However, important issues of particular relevance to PROM assessments, such as missing values, multiple outcomes, and the statistical analysis, require careful attention. ${ }^{32}$ Proper instrument selection is essential for RCTs using PROM outcomes. The application of validated and widely

Table 1. Summary of randomized clinical trials that evaluated PROMs.

\begin{tabular}{|c|c|c|c|c|}
\hline Author (year) & Intervention and sample & $\begin{array}{c}\text { Time } \\
\text { evaluation }\end{array}$ & $\begin{array}{c}\text { PROM } \\
\text { evaluation }\end{array}$ & Main results \\
\hline $\begin{array}{l}\text { Santuchi et al., } \\
2016^{21}\end{array}$ & $\begin{array}{l}\text { Scaling and root planning }(n=45) \text { and } \\
\text { full-mouth debridement }(n=45)\end{array}$ & $\begin{array}{l}\text { Baseline, } 1 \\
\text { and } 6 \text { months }\end{array}$ & OIDP & $\begin{array}{l}\text { Both groups showed significant improvement } \\
\text { on clinical parameters and OIDP; no } \\
\text { significant differences between groups. }\end{array}$ \\
\hline $\begin{array}{l}\text { Åslund et al., } \\
2008^{24}\end{array}$ & $\begin{array}{l}\text { Non-surgical therapy using a } \\
\text { piezo-ceramic device }(\mathrm{n}=30) \text { or curets } \\
(\mathrm{n}=29) \text { in individuals with mild to } \\
\text { moderate periodontitis }\end{array}$ & $\begin{array}{l}\text { Baseline, } \\
\text { treatment, } \\
\text { and } 1,4 \text {, and } \\
8 \text { weeks }\end{array}$ & OHQOL-UK & $\begin{array}{l}\text { Both groups showed improvements in clinical } \\
\text { parameters, pain scores and QoL measures }\end{array}$ \\
\hline $\begin{array}{l}\text { Agado et al., } \\
2012^{25}\end{array}$ & $\begin{array}{l}\text { Utrasonic debridement }(n=10) \text {, hand } \\
\text { instrumentation }(n=10) \text {, and a control } \\
\text { group }(n=10) \text { in chronic obstructive } \\
\text { pulmonary disease patients }\end{array}$ & $\begin{array}{l}\text { Baseline } \\
\text { and } 4 \text { weeks } \\
\text { post-treatment }\end{array}$ & $S G R Q$ & $\begin{array}{l}\text { Total SGRQ-A scores decreased slightly for all } \\
\text { groups with no significant difference among } \\
\text { groups and no significant interaction }\end{array}$ \\
\hline $\begin{array}{l}\text { Santuchi et al., } \\
2015^{26}\end{array}$ & $\begin{array}{l}\text { Scaling and root planning per quadrant } \\
(n=37) \text { and one-stage full-mouth } \\
\text { disinfection }(n=41)\end{array}$ & $\begin{array}{l}\text { Baseline and } \\
6 \text { months }\end{array}$ & $\begin{array}{l}\text { DFS, DAS } \\
\text { and VAS }\end{array}$ & $\begin{array}{l}\text { Patients with higher PROs showed worse } \\
\text { clinical parameters before and after treatment. } \\
\text { After both treatments, fear and anxiety } \\
\text { decreased with no significant differences } \\
\text { between groups. No significant differences in } \\
\text { pain scores between groups }\end{array}$ \\
\hline $\begin{array}{l}\text { Cortelli et al., } \\
2018^{27}\end{array}$ & $\begin{array}{l}\text { Ultrasonic debridement in combination } \\
\text { with essential-oils in diabetic }(n=30) \\
\text { and non-diabetic individuals }(n=30) \text {, } \\
\text { or placebo mouthwash in diabetic } \\
(\mathrm{n}=30) \text { and non-diabetic individuals } \\
\qquad(\mathrm{n}=30)\end{array}$ & $\begin{array}{l}\text { Baseline and } \\
3 \text { months }\end{array}$ & OHQoL-UK & $\begin{array}{l}\text { Combined treatment with EO provided } \\
\text { OHQoL improvements in both systemic } \\
\text { conditions, but not in placebo groups }\end{array}$ \\
\hline $\begin{array}{l}\text { Musskopf et al., } \\
2018^{28}\end{array}$ & $\begin{array}{l}\text { Pregnant women receiving scaling and } \\
\text { root planning/maintenance }(n=96) \\
\text { or supragingival scaling and polishing } \\
\qquad(n=114)\end{array}$ & $\begin{array}{l}\text { Before and } \\
\text { after treatment }\end{array}$ & OHIP-14 & $\begin{array}{l}\text { Both groups showed significant reduction } \\
\text { in OHIP-14 scores; control group had } \\
\text { significantly higher odds of worsening their } \\
\text { OHIP-14 scores and their perception of oral } \\
\text { conditions than test group }\end{array}$ \\
\hline $\begin{array}{l}\text { Zhou et al., } \\
2019^{29}\end{array}$ & $\begin{array}{l}60 \text { CPOD individuals: }(n=20) \text { scaling } \\
\text { and root planning treatment, }(n=20) \\
\text { supragingival scaling treatment and } \\
(n=20) \text { oral hygiene instructions only } \\
\text { with no periodontal treatment }\end{array}$ & $\begin{array}{l}\text { Baseline, } 1 \\
\text { and } 2 \text { years }\end{array}$ & $S G R Q$ & $\begin{array}{l}\text { The impacts scores of two treatment groups } \\
\text { were significantly lower than control group at } \\
2 \text {-year follow-up }\end{array}$ \\
\hline
\end{tabular}

OHQoL-UK: United Kingdom OHQoL questionnaire; SGRQ: St. George's Respiratory Questionnaire; DFS: Dental Fear Survey; DAS: Dental Anxiety Scale VAS: Visual Analogue Scale; OIDP: Oral Impacts on Daily Performance; OHIP-14: Oral Health Impact Profile-14. 
used questionnaires following an interview format is regarded as best practice. In perspective, a combination of PROMs as primary outcome and established periodontal parameters as secondary outcomes may provide a more comprehensive assessment of current and innovative new treatments.

\section{Surrogate outcomes in periodontal trials}

Although a few clinical studies have used CROs such as tooth loss and OHRQoL such as patient satisfaction, post-treatment discomfort/pain and aesthetic perception as primary outcomes, ${ }^{33}$ most RCTs in periodontology have used surrogate parameters as primary outcomes. The most commonly used parameters are mean PPD reduction or CAL gain at initially deeper periodontal sites. ${ }^{34}$ Mean gingival recession and percent root coverage are also frequently used in RCTs focused on esthetics ${ }^{5}$. Unfortunately, there are several drawbacks associated with the use of such parameters, such as: (i) limited evidence that they reflect long-term benefits for patients, (ii) challenging interpretation of the results since clinicians do not use averages to evaluate the result of their treatments in daily clinical practice, and (iii) changes in mean clinical values do not reflect an endpoint for treatment (i.e., disease remission/control) at the patient level.

A possible solution for this conundrum is the use of a surrogate outcome that reflects an endpoint for treatment at the patient level for which there is strong evidence of substantial effect on CROs. This approach would allow the implementation of the "treat-to-target" concept largely used in medicine, but still relatively unknown in dentistry. The idea is to treat a disease until a prespecified clinical or laboratorial target is achieved. A classic example in medicine is the use of a threshold for blood pressure (e.g., $120 / 80 \mathrm{~mm} \mathrm{Hg}$ ) as a surrogate outcome in trials testing medications to prevent myocardial infarction or heart failure. The main challenge of a treatment approach based on the treat-to-target concept is to identify targets that reflect disease remission/control and that may predict meaningful long-term benefits to patient

Researchers and clinicians have been exploring other primary outcome variables to address the above- mentioned shortcomings for surrogate outcomes in periodontology. ${ }^{35-38}$ Presence of residual pockets after therapy has been associated with lack of long-term periodontal stability and disease recurrence. ${ }^{16,39-44}$ 3,12-17 Deep pockets are colonized by a more dysbiotic subgingival biofilm containing higher levels of periodontal pathogens than shallow pockets, ${ }^{45}$ which favors the persistence of periodontal inflammation. In periodontology, two surrogate outcomes based on the number of residual sites at the patient level after active periodontal therapy have been suggested as potential endpoints for treatment in RCTs: Mombelli and co-workers suggested "number of sites with PPD $\geq 5 \mathrm{~mm}$ and bleeding on probing (BOP)" ${ }^{\prime \prime 35,46}$ and Feres and co-workers "presence of at most 4 sites with PPD $\geq 5 \mathrm{~mm}^{36}$ " after treatment ${ }^{8}$. The later criterion was initially suggested as a secondary outcome, ${ }^{36}$ then reported in several RCTs in the literature, ${ }^{38,47-56}$ and finally presented as a primary outcome variable for treatment. ${ }^{37}$ Recently, this outcome was validated in a study that included a comprehensive analysis of 724 patients from the United States, Germany and Brazil. ${ }^{34}$ The validation process was able to demonstrate that the proposed outcome was effective in distinguishing between patients showing signs of periodontal disease remission/control from those showing signs of uncontrolled disease up to 2 years post-treatment. In addition, these patients had a microbial profile more compatible with health up to 2 years post-treatment. ${ }^{53,57}$ Another interesting finding in that study was that full mouth BOP seemed to worsen the results of treatment. Regression models showed that the presence of $>10 \%$ and $>20 \%$ sites with BOP in the mouth post-treatment increases the risk of a patient leaving the endpoint between 1 and 2 years of follow-up, with an OR = 3.5 and 8.7, respectively.

Robust risk assessment studies should be planned in order to establish if these new surrogate endpoints correlate with long-term periodontal stability, tooth survival, OHRQoL, and other patient-centered outcomes. The selection of surrogate outcomes in clinical trials should take into consideration the study objectives since periodontal disease treatment and periodontal reconstruction may require different criteria for success. Table 2 summarizes the main concepts described in this article, with examples. 
Table 2. Summary of concepts and examples.

\begin{tabular}{|c|c|c|}
\hline Type of outcome & Definition & Examples \\
\hline $\begin{array}{l}\text { Clinically relevant } \\
\text { outcomes (CROs) }\end{array}$ & $\begin{array}{l}\text { Outcomes that directly measure how a patient feels, } \\
\text { functions or survives }\end{array}$ & $\begin{array}{c}\text { Death, number of hospitalizations, tooth loss, oral } \\
\text { health-related quality of life }\end{array}$ \\
\hline $\begin{array}{l}\text { Patient-reported outcome } \\
\text { measures (PROMs) }\end{array}$ & $\begin{array}{l}\text { Measurements of any aspect of a patient's health } \\
\text { status that come directly from the patient. PROMs are } \\
\text { considered to be CROs. }\end{array}$ & $\begin{array}{l}\text { Pain/discomfort, self-assessment of function and } \\
\text { esthetics, oral health-related quality of life }\end{array}$ \\
\hline Surrogate outcomes & $\begin{array}{l}\text { Outcomes that are not themselves a direct } \\
\text { measurement of the clinical endpoint. Rather, they are } \\
\text { supposed to be a proxy for the true CRO }\end{array}$ & $\begin{array}{l}\text { Gingival crevicular fluid levels of interleukin- } 1 \beta \text {, } \\
\text { radiographic alveolar bone loss, clinical attachment gain }\end{array}$ \\
\hline Primary outcome & $\begin{array}{l}\text { The pre-specified outcome considered to be of greatest } \\
\text { importance to the study; study design and sample size } \\
\text { calculations are based on the primary outcome }\end{array}$ & $\begin{array}{l}\text { Depending on the objective of the study a given outcome } \\
\text { can be primary or secondary. }\end{array}$ \\
\hline Secondary outcomes & $\begin{array}{l}\text { All other outcomes in the study. The trial is not designed } \\
\text { to evaluate them, so they are exploratory in nature }\end{array}$ & $\begin{array}{c}\text { E.g.: pain assessed using a visual analog scale can } \\
\text { be a primary outcome in an RCT testing an analgesic } \\
\text { and secondary in a RCT comparing two root coverage } \\
\text { surgical techniques }\end{array}$ \\
\hline
\end{tabular}

\section{CONCLUSION}

The proper selection of study outcomes is an essential step during the protocol development of RCTs. Investigators should select CROs that not only provide substantial health benefits, but also are deemed important by patients.

OHRQoL are emerging as preferred primary outcomes in clinical research. Data derived from RCTs support the concept that PROMs are able to accurately assess improvements in patient OHRQoL following periodontal treatment, such as satisfaction, discomfort/pain and aesthetics. Future RTCs using validated PROMs and samples with broader characteristics are necessary to expand the use of PROMs in periodontology.

Surrogate outcomes can be used as proxies when the use of CROs is not feasible. Surrogate outcomes traditionally used in periodontal clinical research do not reflect a treatment endpoint at the patient level that can be easily used to inform decision-making in daily practice. Instead of outcomes based on group averages, we suggest the use of partially validated surrogate outcomes based on the presence of residual "pockets" following treatment, such as the presence of $\leq 4$ sites with PPD $\geq 5 \mathrm{~mm}$. This surrogate outcome has been shown to correlate with disease remission/control following non-surgical periodontal treatment for up to 2 years. Thus, it allows the implementation of a treat-to-target concept in periodontal trials clearly outlining if the intervention has achieved a prespecified treatment target.

A combination of outcomes assessing OHRQoL and clinical parameters reflecting an endpoint for periodontal treatment may provide a more comprehensive assessment of new treatments and interventions.

\section{References}

1. Friedman LM, Furberg CD, DeMets DL, Reboussin DM, Granger CB. Fundamentals of clinical trials. Cham: Springer; 2015. https://doi.org/10.1007/978-3-319-18539-2

2. Chan AW, Tetzlaff JM, Gøtzsche PC, Altman DG., Mann H, Berlin JA, et al. SPIRIT 2013 explanation and elaboration: guidance for protocols of clinical trials. BMJ. 2013 Jan;346:e7586. https://doi.org/10.1136/bmi.e7586

3. Moher D, Hopewell S, Schulz KF, Montori V, Gøtzsche PC, Devereaux PJ, et al. CONSORT 2010 explanation and elaboration: updated guidelines for reporting parallel group randomised trials. J Clin Epidemiol. 2010 Aug;63(8):e1-37. https://doi.org/10.1016/i.jclinepi.2010.03.004 
4. Lewis JA. Statistical principles for clinical trials (ICH E9): an introductory note on an international guideline. Stat Med. 1999 Aug;18(15):1903-42. https://doi.org/10.1002/(SICI)1097-0258(19990815)18:15<1903::AID-SIM188>3.0.CO;2-F

5. Schulz KF, Grimes DA. Multiplicity in randomised trials I: endpoints and treatments. Lancet. 2005 Apr;365(9470):1591-5. https://doi.org/10.1016/S0140-6736(05)66461-6

6. Goodman SN, Fanelli D, loannidis JP. What does research reproducibility mean? Sci Transl Med. 2016 Jun;8(341):96-102. https://doi.org/10.1126/scitransImed.aaf5027

7. Li T, Mayo-Wilson E, Fusco N, Hong H, Dickersin K. Caveat emptor: the combined effects of multiplicity and selective reporting 11 Medical and Health Sciences 1117 Public Health and Health Services. Trials. 2018;19(1):4-9. https://doi.org/10.1186/s13063-018-2888-9

8. Chan AW, Hróbjartsson A, Haahr MT, Gøtzsche PC, Altman DG. Empirical evidence for selective reporting of outcomes in randomized trials: comparison of protocols to published articles. JAMA. 2004 May;291(20):2457-65. https://doi.org/10.1001/jama.291.20.2457

9. Sendyk DI, Rovai ES, Souza NV, Deboni MC, Pannuti CM. Selective outcome reporting in randomized clinical trials of dental implants. J Clin Periodontol. 2019 Jul;46(7):758-65. https://doi.org/10.1111/icpe.13128

10. Zarin DA, Tse T, Williams RJ, Califf RM, Ide NC. The ClinicalTrials.gov results database_update and key issues. N Engl J Med. 2011 Mar;364(9):852-60. https://doi.org/10.1056/NEJMsa1012065

11. Mayo-Wilson E, Fusco N, Li T, Hong H, Canner JK, Dickersin K. Multiple outcomes and analyses in clinical trials create challenges for interpretation and research synthesis. J Clin Epidemiol. 2017 Jun;86:39-50. https://doi.org/10.1016/i.jclinepi.2017.05.007

12. Pannuti CM, Sendik DI, Graças YT, Takai SL, Sabóia VPA, Romito GA, et al. Clinically relevant outcomes in dental clinical trials: challenges and proposals. Braz Oral Res. 2020;34(suppl 2):1-10. https://doi.org/10.1590/1807-3107bor-2020.vol34.0073

13. Fleming TR, Powers JH. Biomarkers and surrogate endpoints in clinical trials. Stat Med. 2012 Nov;31(25):2973-84. https://doi.org/10.1002/sim.5403

14. Heneghan C, Goldacre B, Mahtani KR. Why clinical trial outcomes fail to translate into benefits for patients. Trials. 2017 Mar;18(1):122. https://doi.org/10.1186/s13063-017-1870-2

15. Hujoel PP. Endpoints in periodontal trials: the need for an evidence-based research approach. Periodontol 2000. 2004;36(1):196-204. https://doi.org/10.1111/j.1600-0757.2004.03681.x

16. Graetz C, Plaumann A, Schlattmann P, Kahl M, Springer C, Sälzer S, et al. Long-term tooth retention in chronic periodontitis - results after 18 years of a conservative periodontal treatment regimen in a university setting. J Clin Periodontol. 2017 Feb;44(2):169-77. https://doi.org/10.1111/icpe.12680

17. Kotronoulas G, Kearney N, Maguire R, Harrow A, Di Domenico D, Croy S, et al. What is the value of the routine use of patient-reported outcome measures toward improvement of patient outcomes, processes of care, and health service outcomes in cancer care? A systematic review of controlled trials. J Clin Oncol. 2014 May;32(14):1480-501. https://doi.org/10.1200/JCO.2013.53.5948

18. El Sayed N, Baeumer A, El Sayed S, Wieland L, Weber D, Eickholz P, et al. Twenty years later: oral health-related quality of life and standard of treatment in patients with chronic periodontitis. J Periodontol. 2019 Apr;90(4):323-30. https://doi.org/10.1002/JPER.18-0417

19. Cunha-Cruz J, Hujoel PP, Kressin NR. Oral health-related quality of life of periodontal patients. J Periodontal Res. 2007 Apr;42(2):169-76. https://doi.org/10.1111/j.1600-0765.2006.00930.x

20. Needleman I, McGrath C, Floyd P, Biddle A. Impact of oral health on the life quality of periodontal patients. J Clin Periodontol. 2004 Jun;31(6):454-7. https://doi.org/10.1111/j.1600-051X.2004.00498.x

21. Santuchi CC, Cortelli JR, Cortelli SC, Cota LO, Fonseca DC, Alencar CO, et al. Scaling and root planing per quadrant versus one-stage full-mouth disinfection: assessment of the impact of chronic periodontitis treatment on quality of life-a clinical randomized, controlled trial. J Periodontol. 2016 Feb;87(2):114-23. https://doi.org/10.1902/jop.2015.150105

22. Meusel DR, Ramacciato JC, Motta RH, Brito Júnior RB, Flório FM. Impact of the severity of chronic periodontal disease on quality of life. J Oral Sci. 2015 Jun;57(2):87-94. https://doi.org/10.2334/josnusd.57.87

23. Borges TF, Regalo SC, Taba Junior M, Siéssere S, Mestriner Junior W, Semprini M. Changes in masticatory performance and quality of life in individuals with chronic periodontitis. J Periodontol. 2013 Mar;84(3):325-31. https://doi.org/10.1902/jop.2012.120069

24. Åslund M, Suvan J, Moles DR, D'Aiuto F, Tonetti MS. Effects of two different methods of non-surgical periodontal therapy on patient perception of pain and quality of life: a randomized controlled clinical trial. J Periodontol. 2008 Jun;79(6):1031-40. https://doi.org/10.1902/jop.2008.070394

25. Agado BE, Crawford B, DeLaRosa J, Bowen DM, Peterson T, Neill K, et al. Effects of periodontal instrumentation on quality of life and illness in patients with chronic obstructive pulmonary disease: a pilot study. J Dent Hyg. 2012;86(3):204-14.

26. Santuchi CC, Cortelli SC, Cortelli JR, Cota LO, Alencar CO, Costa FO. Pre- and post-treatment experiences of fear, anxiety, and pain among chronic periodontitis patients treated by scaling and root planing per quadrant versus one-stage full-mouth disinfection: a 6-month randomized controlled clinical trial. J Clin Periodontol. 2015 Nov;42(11):1024-31. https://doi.org/10.1111/icpe.12472 
27. Cortelli SC, Costa FO, Gargioni-Filho A, Aquino DR, Cota LO, Scherma AP, et al. Impact of gingivitis treatment for diabetic patients on quality of life related to periodontal objective parameters: A randomized controlled clinical trial. Arch Oral Biol. 2018 Feb;86:80-6. https://doi.org/10.1016/i.archoralbio.2017.11.010

28. Musskopf ML, Milanesi FC. Rocha JM, Fiorini T, Moreira CHC, Susin C, et al. Oral health related quality of life among pregnant women: a randomized controlled trial. Braz Oral Res. 2018 Jan;32:002. https://doi.org/10.1590/1807-3107bor-2018.vol32.0002

29. Zhou X, Liu ZQ, Li W, Wang ZM. [Influence of non-surgical periodontal treatment on the quality of life in chronic obstructive pulmonary disease patients with chronic periodontitis]. Zhonghua Kou Qiang Yi Xue Za Zhi. 2019 Mar;54(3):151-6. https://doi.org/10.3760/cma.j.issn.1002-0098.2019.03.002

30. Wittneben JG, Wismeijer D, Brägger U, Joda T, Abou-Ayash S. Patient-reported outcome measures focusing on aesthetics of implant- and tooth-supported fixed dental prostheses: a systematic review and meta-analysis. Clin Oral Implants Res. 2018 Oct;29(S16 Suppl 16):224-40. https://doi.org/10.1111/clr.13295

31. Cairo F, Barootchi S, Tavelli L, Barbato L, Wang HL, Rasperini G, et al. Aesthetic-And patient-related outcomes following root coverage procedures: A systematic review and network meta-analysis. J Clin Periodontol. 2020 Nov;47(11):1403-15. https://doi.org/10.1111/jcpe.13346

32. Valderas JM, Alonso J. Patient reported outcome measures: a model-based classification system for research and clinical practice. Qual Life Res. 2008 Nov; 17(9):1125-35. https://doi.org/10.1007/s11136-008-9396-4

33. Pannuti CM, Sendyk DI, Graças YT, Takai SL, Sabóia VPA, Romito GA, et al. Clinically relevant outcomes in dental clinical trials: challenges and proposals. Braz Oral Res. 2020;34(suppl 2). https://doi.org/10.1590/1807-3107bor-2020.vol34.0073

34. Feres M, Retamal-Valdes B, Faveri M, Duarte P, Shibli J, Soares GM, et al. Proposal of a Clinical Endpoint for Periodontal Trials: The Treat-to-Target Approach. J Int Acad Periodontol. 2020 Apr;22(2):41-53.

35. Cionca N, Giannopoulou C, Ugolotti G, Mombelli A. Amoxicillin and metronidazole as an adjunct to full-mouth scaling and root planing of chronic periodontitis. J Periodontol. 2009 Mar;80(3):364-71. https://doi.org/10.1902/jop.2009.080540

36. Feres M, Soares GM, Mendes JA, Silva MP, Faveri M, Teles R, et al. Metronidazole alone or with amoxicillin as adjuncts to non-surgical treatment of chronic periodontitis: a 1-year double-blinded, placebo-controlled, randomized clinical trial. J Clin Periodontol. 2012 Dec;39(12):1149-58. https://doi.org/10.1111/icpe.12004

37. Borges I, Faveri M, Figueiredo LC, Duarte PM, Retamal-Valdes B, Montenegro SC, et al. Different antibiotic protocols in the treatment of severe chronic periodontitis: a 1-year randomized trial. J Clin Periodontol. 2017 Aug;44(8):822-32. https://doi.org/10.1111/jicpe.12721

38. Harks I, Koch R, Eickholz P, Hoffmann T, Kim TS, Kocher T, et al. Is progression of periodontitis relevantly influenced by systemic antibiotics? A clinical randomized trial. J Clin Periodontol. 2015 Sep;42(9):832-42. https://doi.org/10.1111/icpe.12441

39. Claffey N, Egelberg J. Clinical indicators of probing attachment loss following initial periodontal treatment in advanced periodontitis patients. J Clin Periodontol. 1995 Sep;22(9):690-6. https://doi.org/10.1111/j.1600-051X.1995.tb00828.x

40. Renvert S, Persson GR. A systematic review on the use of residual probing depth, bleeding on probing and furcation status following initial periodontal therapy to predict further attachment and tooth loss. J Clin Periodontol. 2002;29 Suppl 3:82-9. https://doi.org/10.1034/j.1600-051X.29.s-3.2.x

41. Lang NP, Tonetti MS. Periodontal risk assessment (PRA) for patients in supportive periodontal therapy (SPT). Oral Health Prev Dent. $2003 ; 1(1): 7-16$.

42. Chapple IL, Mealey BL, Van Dyke TE, Bartold PM, Dommisch H, Eickholz P, et al. Periodontal health and gingival diseases and conditions on an intact and a reduced periodontium: Consensus report of workgroup 1 of the 2017 World Workshop on the Classification of Periodontal and Peri-Implant Diseases and Conditions. J Periodontol. 2018 Jun;89 Suppl 1:S74-84. https://doi.org/10.1002/JPER.17-0719

43. Loos BG, Needleman I. Endpoints of active periodontal therapy. J Clin Periodontol. 2020 Jul;47(S22 Suppl 22):61-71. https://doi.org/10.1111/jcpe.13253

44. Matuliene G, Pjetursson BE, Salvi GE, Schmidlin K, Brägger U, Zwahlen M, et al. Influence of residual pockets on progression of periodontitis and tooth loss: results after 11 years of maintenance. J Clin Periodontol. 2008 Aug;35(8):685-95. https://doi.org/10.1111/j.1600-051X.2008.01245.x

45. Pérez-Chaparro PJ, McCulloch JA, Mamizuka EM, Moraes AD, Faveri M, Figueiredo LC, et al. Do different probing depths exhibit striking differences in microbial profiles? J Clin Periodontol. 2018 Jan;45(1):26-37. https://doi.org/10.1111/icpe.12811

46. Mombelli A, Almaghlouth A, Cionca N, Courvoisier DS, Giannopoulou C. Differential benefits of amoxicillin-metronidazole in different phases of periodontal therapy in a randomized controlled crossover clinical trial. J Periodontol. 2015 Mar;86(3):367-75. https://doi.org/10.1902/jop.2014.140478

47. Mestnik MJ, Feres M, Figueiredo LC, Soares G, Teles RP, Fermiano D, et al. The effects of adjunctive metronidazole plus amoxicillin in the treatment of generalized aggressive periodontitis: a 1-year double-blinded, placebo-controlled, randomized clinical trial. J Clin Periodontol. 2012 Oct;39(10):955-61. https://doi.org/10.1111/j.1600-051X.2012.01932.x 
48. Santos NCC, Andere NM, Araujo CF, Marco AC, Kantarci A, Van Dyke TE, et al. Omega-3 PUFA and aspirin as adjuncts to periodontal debridement in patients with periodontitis and type 2 diabetes mellitus: randomized clinical trial. J Periodontol. 2020 Oct;91(10):1318-27. https://doi.org/10.1002/JPER.19-0613

49. Teughels W, Durukan A, Ozcelik O, Pauwels M, Quirynen M, Haytac MC. Clinical and microbiological effects of Lactobacillus reuteri probiotics in the treatment of chronic periodontitis: a randomized placebo-controlled study. J Clin Periodontol. 2013 Nov;40(11):1025-35. https://doi.org/10.1111/icpe.12155

50. Faveri M, Rebello A, Dias RO, Borges-Junior I, Duarte PM, Figueiredo LC, et al. Clinical and microbiologic effects of adjunctive metronidazole plus amoxicillin in the treatment of generalized chronic periodontitis: smokers versus non-smokers. J Periodontol. 2014 Apr;85(4):581-91. https://doi.org/10.1902/jop.2013.130278

51. Laleman I, Yilmaz E, Ozcelik O, Haytac C, Pauwels M, Herrero ER, et al. The effect of a streptococci containing probiotic in periodontal therapy: a randomized controlled trial. J Clin Periodontol. 2015 Nov;42(11):1032-41. https://doi.org/10.1111/icpe.12464

52. Tekce M, Ince G, Gursoy H, Dirikan Ipci S, Cakar G, Kadir T, et al. Clinical and microbiological effects of probiotic lozenges in the treatment of chronic periodontitis: a 1-year follow-up study. J Clin Periodontol. 2015 Apr;42(4):363-72. https://doi.org/10.1111/jcpe.12387

53. Tamashiro NS, Duarte PM, Miranda TS, Maciel SS, Figueiredo LC, Faveri M, et al. Amoxicillin Plus Metronidazole Therapy for Patients with Periodontitis and Type 2 Diabetes: A 2-year Randomized Controlled Trial. J Dent Res. 2016 Jul;95(7):829-36. https://doi.org/10.1177/0022034516639274

54. Cosgarea R, Heumann C, Juncar R, Tristiu R, Lascu L, Salvi GE, et al. One year results of a randomized controlled clinical study evaluating the effects of non-surgical periodontal therapy of chronic periodontitis in conjunction with three or seven days systemic administration of amoxicillin/metronidazole. PLoS One. 2017 Jun;12(6):e0179592. https://doi.org/10.1371/journal.pone.0179592

55. Araujo CF, Andere NM, Santos NCC, Mathias-Santamaria IF, Reis AA, de Oliveira LD, et al. Two different antibiotic protocols as adjuncts to one-stage full-mouth ultrasonic debridement to treat generalized aggressive periodontitis: A pilot randomized controlled clinical trial. J Periodontol. 2019 Dec;90(12):1431-40. https://doi.org/10.1002/JPER.18-0399

56. Almeida ML, Duarte PM, Figueira EA, Lemos JC, Nobre CM, Miranda TS, et al. Effects of a full-mouth disinfection protocol on the treatment of type-2 diabetic and non-diabetic subjects with mild-to-moderate periodontitis: one-year clinical outcomes. Clin Oral Investig. 2020 Jan;24(1):333-41. https://doi.org/10.1007/s00784-019-02927-8

57. Feres M, Figueiredo LC, Soares GM, Faveri M. Systemic antibiotics in the treatment of periodontitis. Periodontol 2000. 2015 Feb;67(1):131-86. https://doi.org/10.1111/prd.12075 